\title{
Cancers of the lung and nasal sinuses in nickel workers: a reassessment of the period of risk
}

\author{
R. DOLL ${ }^{1}$, J. D. MATHEWS', AND L. G. MORGAN 3 \\ From the ${ }^{1}$ Department of the Regius Professor of Medicine, Radcliffe Infirmary, Oxford, ${ }^{2}$ Department of \\ Medicine, University of Melbourne, Royal Melbourne Hospital, and ${ }^{3}$ International Nickel Limited, Clydach
}

ABSTRACT Nine hundred and sixty-seven men who were employed in a nickel refinery in South Wales on at least two occasions five or more years apart before 1945 have been followed up, and the mortality rates from different causes related to the date of their first employment. Previous reports suggested that the occupational risks of lung and nasal sinus cancer had been eliminated by 1925 . It is now shown that the risk persisted until 1930, which accords better with the temporal changes in the process.

Occupational risks of lung and nasal sinus cancer in workers employed in a nickel refinery in South Wales have been known for 40 years (Bridge, 1933; Amor, 1939; Hill, 1939). Similar risks have been reported from Canada (Sutherland, 1959; Mastromatteo, 1967) and Norway (Pedersen et al., 1973), and an increased incidence of respiratory tract cancer in nickel workers has been observed in the German Democratic Republic, Japan, and the USSR (see IARC, 1976). The risk was first attributed to exposure to nickel carbonyl, a gas that was produced in the refining of nickel only in South Wales, and the cancers were recognised for legal purposes as occupational in origin only when they occurred in men working 'in a factory where nickel is produced by decomposition of a gaseous nickel compound'. It is clear that metallic nickel and nickel carbonyl are carcinogenic under certain experimental conditions (see Sunderman, 1973, for review); yet, ironically, the epidemiological evidence points away from the nickel carbonyl process and incriminates exposure to dust from the preliminary processes, particularly the calcination of impure nickel copper sulphide $\left(\mathrm{Ni}_{3} \mathrm{~S}_{2}-\mathrm{Cu}_{2} \mathrm{~S}\right)$ to nickel copper oxide (Morgan, 1958; Doll, 1958; Sutherland, 1959; Pedersen et al., 1973).

One of the difficulties in characterising the agent has been the belief that the risk was eliminated from the Welsh refinery by 1925 (Doll et al., 1970), at which time crude matte was still being treated under conditions that gave rise to considerable dust and when the existence of the risk had not yet been suspected. The number of men who were first em-

Received for publication 24 September 1976 Accepted for publication 19 January 1977 ployed during the latter half of the 1920 s was, however, small and a continuing risk during the period 1925-29 may well have been overlooked. We have, therefore, sought to obtain more information by extending the previous epidemiological observations, both by continuing the period of follow-up and by including a further group of men who were known to have been employed in 1929.

\section{Method}

The men to be studied were identified from the weekly pay-sheets which had been maintained by the Company from a very early period and which listed all those who received an hourly wage (that is, the manual workers of the period) by name and works reference number, irrespective of whether they had been at work that week or not. In our previous study, pay-sheets had been inspected for the first week in April of the years 1934, 1939, 1944, and 1949, and all men were included whose names were listed on any two of the sheets, unless they were noted on one of the sheets as having been in the Armed Forces or transferred elsewhere for war work. By this means the population was limited to men who were likely to have been employed for at least 5 years, and who were alive and employed at some time after the first of April 1939. We have now extended the study by examining pay-sheets for the first week in April 1929. In this way we have extended backwards the years at risk for 574 men who were included in the previous study and have added a further 122 men whose names were recorded on the pay-sheet in April 1929 and on one of the sets of sheets for the four later years. 
The names of all the men were sought in the Company's register of new employees and the years of first employment recorded. Ages were obtained either from the same register or, if missing, from elsewhere. Two men who could not be identified in the register were excluded from the study.

Men included in our previous study had been followed until the date of their death or the beginning of 1967 , whichever was the earlier. We have now extended the follow-up to the beginning of 1972. Thirty-seven men $(3.8 \%)$ could not be traced to this date and they were excluded from the date when they were last known to have been employed. Copies of the death certificates were obtained for all who were known to have died and the cause of death was classified according to the 7th Revision of the International Classification of Causes of Death (World Health Organization, 1957). The use of these rules for all periods rather than the ones that were current at the time of death has no effect on the estimated numbers of deaths attributed to cancers of the lung and nose.

Because of the method of selection, no men came under observation until 1934. The man-years at risk were, therefore, calculated for the period 1934-71. The numbers of deaths that would have been expected if the men had suffered the normal mortality in England and Wales as a whole were calculated by multiplying the man-years at risk in each 5-year age group and each calendar period (1934-38, 1939-43, $1944-48,1949-53,1954-58,1959-63$, and 1964-71) by the corresponding national mortality rates. Nasal cancer rates were not available before 1940 and the rates for 1940 were used for the earlier years.

\section{Results}

Nine hundred and sixty-seven men fulfilled the selection criteria, 689 of whom died before 1 January 1972. Table 1 shows the numbers of men first employed at different times before 1944, the number of man-years at risk, and the total mortality, observed and expected, from all causes.

Table 2 shows the numbers of deaths observed and expected by year of the man's first employment and cause of death. For the employees as a whole the risk of death from carcinoma of the nasal sinus was between 300 and 700 times the national average if they started work before 1920, and about 100 times the national average if they started work between 1920 and 1925 . No deaths were attributed to nasal sinus cancer in men who started work after 1924, but one man who started in 1929 is known to have developed a cancer of the ethmoid sinus. His death, which occurred in 1967 at 73 years of age, was attributed to heart failure due to aortic stenosis with a transitional cancer of the ethmoid referred to as a contributory cause.

The mortality from lung cancer followed a similar pattern. For men who started work before 1920, the mortality was between 6 and 11 times the national average. Thereafter, the risk declined to $5 \cdot 2,2 \cdot 5$, and 1.5 times the national average for men who started in 1920-24, 1925-29, and 1930-44 respectively. The excess mortality was statistically significant for men who were first employed in 1925-29 (P < 0.02) but not for men who were first employed in 1930-44.

The excess mortality from lung cancer combined with the occurrence of one case of nasal cancer in a man who was first employed in 1925-29 provides strong evidence that some element of risk persisted in this period.

The mortality from other cancers and from all other causes was close to that expected, with no evidence of any regular trend with date of first employment. Mortality rates were, however, somewhat less than expected for men employed before 1915. This was not due to a higher rate of loss to follow-up, as most of the men who were untraced were first employed after 1930. Moreover, 117 out of the 119 men who were first employed before 1915 are known to have died. The deficiency could have arisen if some extra care had been taken to trace back the date of first employment of men who died of an occupational cancer over and above that taken for survivors or for men who died of other causes. If this were so, it would have resulted in a slight overestimate of the risk of occupational cancers and an under-estimate of the risk from other causes in the two earliest employment groups.

\section{Discussion}

The chronological changes in the refinery process were reviewed by Morgan (1958). The changes in the feed material are summarised in Table 3, which shows that there was a major change in 1933. There were, however, many other changes which took place over the years and may have contributed to a change in the risk.

The original calciners, which burned sulphur from the raw material, were altered in 1911 and for some time the operators, who tended to leave the sides off, were exposed to more dust than they had been previously. In 1924 the calciners were further altered to a double-deck type which reduced the exposure to dust, although by modern standards the surrounding atmosphere was still very dusty. In 1924, also, cotton face pads were introduced to provide personal protection. These were particularly effective against the large particles, which otherwise were likely to be deposited in the nose, and they rapidly came to be accepted by a high proportion of the men. 
Table 1 Number of men first employed at different periods and mortality observed and expected from all causes

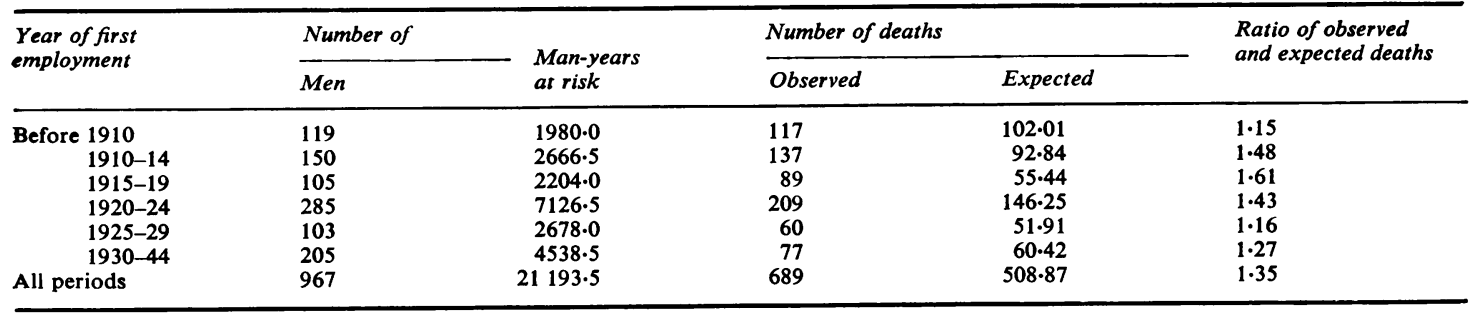

Table 2 Mortality by cause and year of first employment

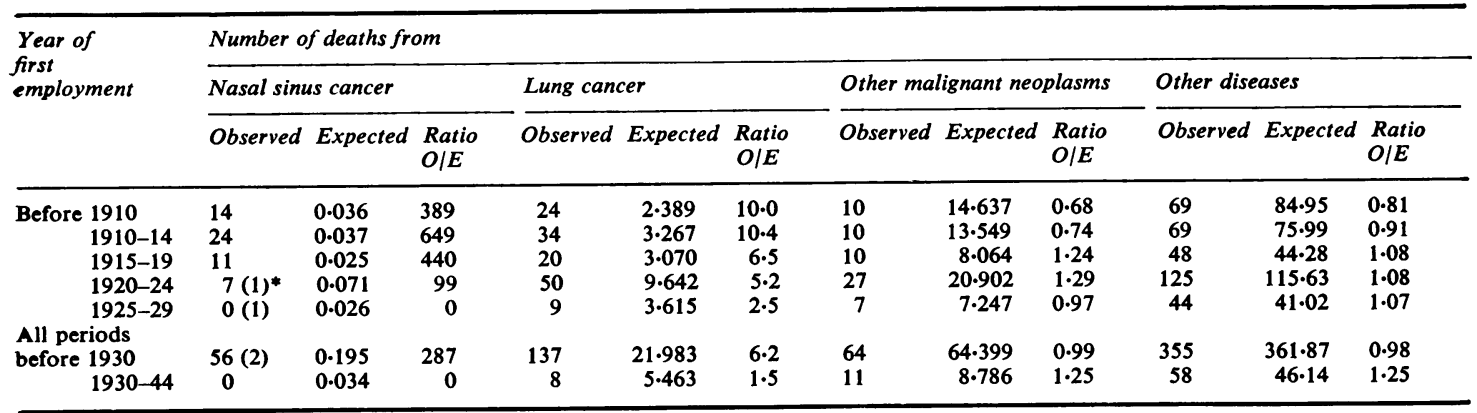

* Number of cases of nasal sinus cancer referred to as an associated cause of death shown in parentheses.

Table 3 Chronological changes in the feed material at the refinery

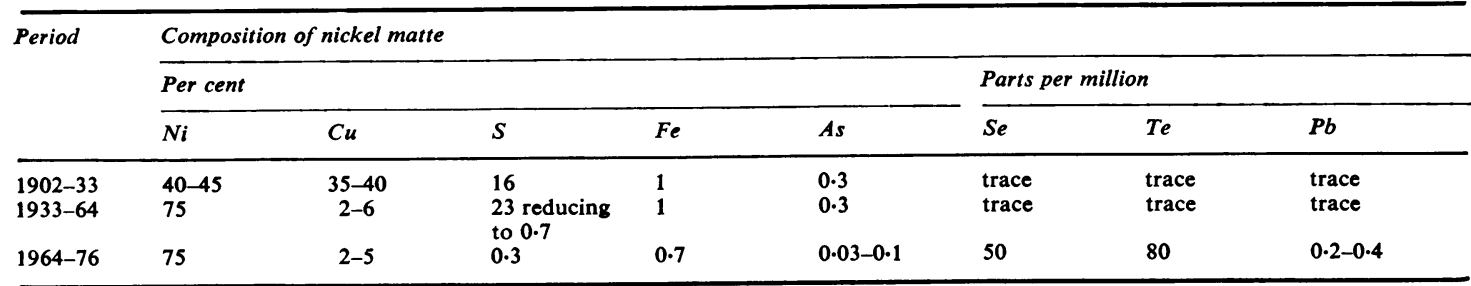

A small amount of arsenic was always present in the matte, but much larger amounts were present in the sulphuric acid which was used to leach the copper. Approximately $\mathbf{4 0}$ tonnes a year used to be imported in the sulphuric acid, the maximum being 63 tonnes in 1919. From 1921, the source of supply was changed and the amount of arsenic to which the men were exposed was rapidly reduced.

Morgan's (1958) investigation linked the risk with exposure to dust from the preliminary processes, particularly from the calciners but also from the copper sheds. Our new finding, that the risk continued until 1930, accords with the changes that affected these parts of the process better than the previous belief that the risk was eliminated in 1925 . A detailed examination of the employment histories of the 967 men who formed the subject of our present study is now being undertaken, in the hope that it will be possible to define the location of the risk more exactly.

\section{References}

Amor, A. J. (1939). Bericht über den VIII internationalen Kongress für Unfallmedizin und Berufskrankheiten. Frankfurt am Main, September 1938, 2, 941. Thieme: Leipzig.

Bridge, J. C. (1933). Annual report of the chief inspector of factories and workshops for the year 1932, pp. 103-104. HMSO: London.

Doll, R. (1958). Cancer of the lung and nose in nickel workers. British Journal of Industrial Medicine, 15, 217-223.

Doll, R., Morgan, L. G., and Speizer, F. (1970). Cancers of the lung and nasal sinuses in nickel workers. British Journal of Cancer, 24, 623-632.

Hill, A. B. (1939). Report to Mond Nickel Company, cited by Morgan (1958).

IARC (1976). IARC Monographs on the Evaluation of 
Carcinogenic Risk of Chemicals to Man, Volume 11. International Agency for Research on Cancer: Lyon.

Mastromatteo, E. (1967). Nickel: a review of its occupational health aspects. Journal of Occupational Medicine, 9, 127-136.

Morgan, J. G. (1958). Some observations on the incidence of respiratory cancer in nickel workers. British Journal of Industrial Medicine, 15, 224-234.

Pedersen, E., Hogetveit, A. C., and Andersen, A. (1973). Cancer of respiratory organs among workers at a nickel refinery in Norway. International Journal of Cancer, 12 , $32-41$.
Sunderman, F. W. (1973). The current status of nickel carcinogenesis. Annals of Clinical Laboratory Science, 3, 156-180.

Sutherland, R. B. (1959). Respiratory cancer mortality in workers employed in an Ontario nickel refinery covering the period 1930 to 1957. Report of the Division of Industrial Hygiene, Ontario Department of Health, November 1959 (unpublished). Cited by Mastromatteo (1967).

World Health Organization (1957). Manual of the international statistical classification of diseases, injuries and causes of death, Seventh revision. WHO: Geneva. 